\title{
Photoreduction of Benzophenone in Green Chemistry Using an Alternate Solvent Ethyl Alcohol
}

\section{Geeta Verma*}

Department of Chemistry, Chandra Shehkar Azad Government Post Graduate Nodal College Sehore, Madhya Pradesh, India

\begin{abstract}
Green chemistry is an approach to the synthesis, processing and use of chemicals that reduces risks to humans and the environment. A synthesis of benzopinacol from benzophenone is carried out using ethanol as a solvent. This is a free radical reaction and reduction of benzophenone occurred by sunlight via UV radiation. Benzopinacol is a catalyst of the formation of unsaturated polyesters. It is also used as an organic synthesis intermediate and as an initiator of polymerization by free radicals. Characterization of Benzopinacol was done by using spectroscopic technique like IR, NMR etc. Results positively show that solvent ethyl alcohol can be used as an alternative for photoreduction of benzphenone in case of non-availability of isopropyl alcohol.
\end{abstract}

Keywords: Photoreduction; IR; NMR; Benzpinacol; Benzophenone; Free radical

\section{Introduction}

\section{Prevention is better than cure}

Green chemistry is the design of chemical products and processes that reduce or eliminate the use and generation of hazardous substances. It relies on a set of 12 principles that can be used to design or re-design molecules, materials and chemical transformations to be safer for human health and the environment [1,2]. The incorporation of green chemistry principles by University Grant commission New Delhi (201314 ), into the post graduate curriculum has fueled a fundamentally new approach to the teaching of chemistry. Green solvents are generally derived from renewable resources and biodegrade to innocuous, often naturally occurring product $[3,4]$. Ehtyl alcohol is one of them. Solar energy is a renewable free source of energy that is sustainable and totally inexhaustible, unlike fossil fuels that are finite [5]. Generally, the term, photochemistry is used to describe a chemical reaction caused by absorption of ultraviolet (wavelength from 100 to 400 $\mathrm{nm})$, visible light $(400-750 \mathrm{~nm})$ or infrared radiation $(750-2500 \mathrm{~nm})$. Photoreduction of benzophenone to benzpinacol is carried out by using alternate renewable source of solvent i.e., ethyl alcohol. benzopinacol is a catalyst for the formation of unsaturated polyesters. It is also used as an organic synthesis intermediate and as an initiator of polymerization by free radicals. Bromoacetyl derivatives of benzopinacol are known as flame retardant initiators for the polymerization of unsaturated polyester (UPE) systems. Additionally, silyl and phosphorus ethers of benzopinacol as flame retardant initiators for unsaturated polyester UPE systems have been also reported [6].

\section{Materials and Methods}

The melting points determined by open capillary tube by electrical melting point apparatus and were uncorrected. FTIR spectra were recorded on Perkin Elmer (4000-400 $\left.\mathrm{cm}^{-1}\right)$. ${ }^{1} \mathrm{H}$ NMR spectra were recorded on Bruker, $300 \mathrm{MHz}$, PMR Spectrophotometer using $\mathrm{CDCL}_{3}$ as a solvent with TMS as an internal standard. The chemical shift are expressed in $\delta, \mathrm{ppm}$. All spectral characterizations were carried out at Central Drug Research Institute, Lucknow.

\section{Mechanism in ethyl alcohol}

Primary process is the excitation of benzophenone. Absorption of light of the appropriate wavelength around $350 \mathrm{~nm}$ for benzophenone generates free radicals. Ethyl alcohol acts as both solvent and reagent in this reaction. Ultra violet light is absorbed by the benzophenone and an intersystem crossing occurs to produce a di radical a molecule with two unpaired electrons. The benzophenone diradical then abstracts a hydrogen atom from the solvent and dimerises, yielding benzpinacol and acetaldehyde [7].

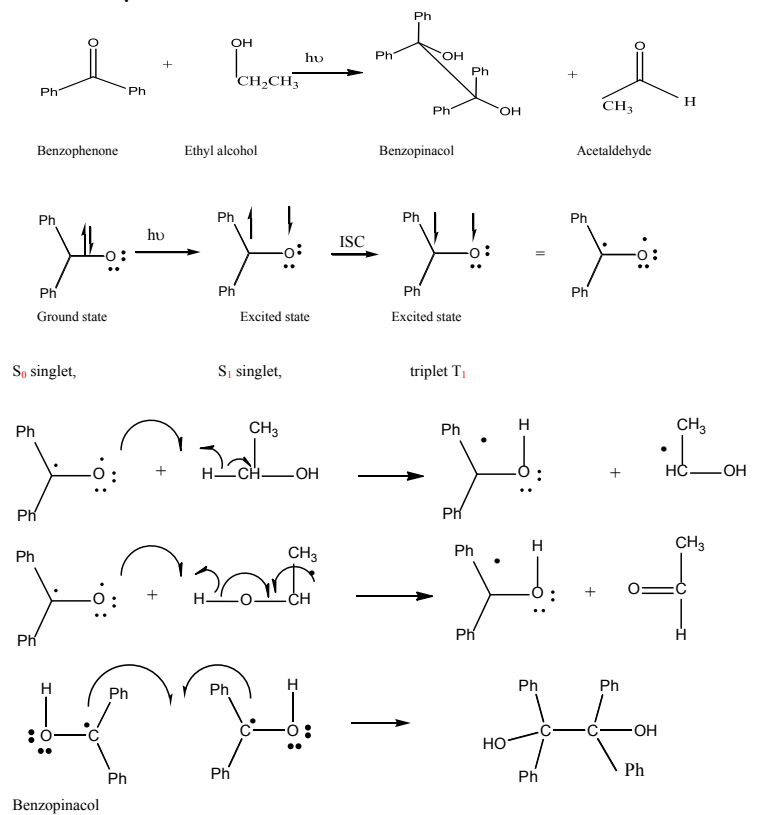

*Corresponding author: Geeta Verma, Assistant Professor, Department of Chemistry, Chandra Shehkar Azad Government Post Graduate Nodal College, Madhya Pradesh, India, Tel: +919425650505; E-mail: drgitaverma@yahoo.co.in

Received June 26, 2017; Accepted July 05, 2017; Published September 13, 2017

Citation: Geeta V (2017) Photoreduction of Benzophenone in Green Chemistry Using an Alternate Solvent Ethyl Alcohol. Chem Sci J 8: 165. doi: 10.4172/21503494.1000165

Copyright: (c) 2017 Geeta V. This is an open-access article distributed under the terms of the Creative Commons Attribution License, which permits unrestricted use, distribution, and reproduction in any medium, provided the original author and source are credited. 
Citation: Geeta V (2017) Photoreduction of Benzophenone in Green Chemistry Using an Alternate Solvent Ethyl Alcohol. Chem Sci J 8: 165. doi: 10.4172/2150-3494.1000165

\section{Experimental}

About $2 \mathrm{gm}$ of benzophenone was allowed to dissolve in $5 \mathrm{ml}$ of ethyl alcohol with gentle warming. After all solid was completely dissolved, the test tube was filled with ethanol to the neck and one drop of glacial acetic acid was added to prevent basic cleavage of the desired product. A cork was inserted and para film was wrapped around the mouth of the test tube and kept at sunny location to complete the reaction. After four to five days white shinning crystals of benzpinacol were separate out. Chilled the test tube in an ice bath and product was collected by vacuum filtration. The crystals were dried overnight and melting point of final compound was determined by open capillary tube method. Calculate the percentage yield for product. Practical yield was found to be $40 \%$ [7-10].

\section{Data analysis}

IR: $1720 \quad(\mathrm{C}=-\mathrm{O}), \quad 2945-75(=\mathrm{C}-\mathrm{H} \quad$ str. $), \quad 2875(-\mathrm{C}-\mathrm{H} \quad$ str. $)$; benzophenone (Figure 1).

IR: $3400-3650$ (O-H), 2945-75(=C-H str.), 2875(-C-H str.); benzpinacol (Figure 2).

${ }^{1} \mathrm{H}$ NMR: $\delta$ 7.0-7.5 (m $10 \mathrm{H}$, Ar-H), (Figure 3), melting point $48^{\circ} \mathrm{C}$.

${ }^{1} \mathrm{H}$ NMR: $\delta 3.0(\mathrm{~s} 2 \mathrm{H}, \mathrm{OH}), 7.0-7.5(\mathrm{~m} 20 \mathrm{H}, \mathrm{Ar}-\mathrm{H})$, (Figure 4), melting point $185^{\circ} \mathrm{C}$.

\section{Results and Discussion}

In this experiment it is aimed to synthesise benzpinacol through

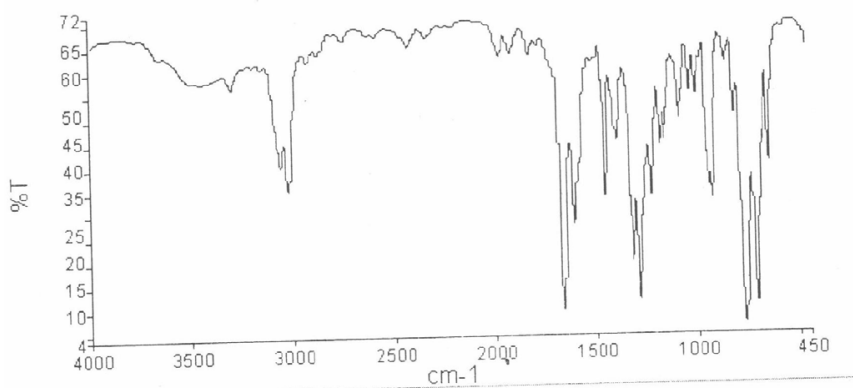

Figure 1: FTIR of Benzophenone.

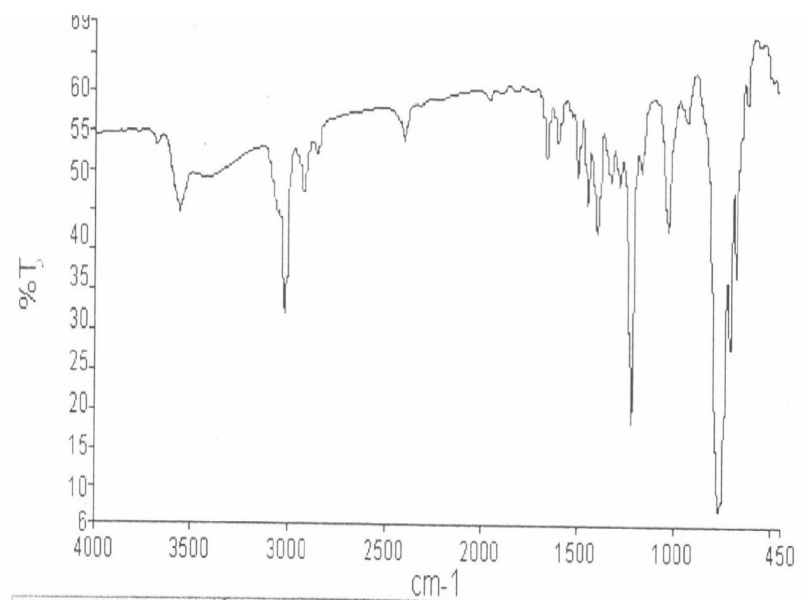

Figure 2: FTIR of benzpinacol.
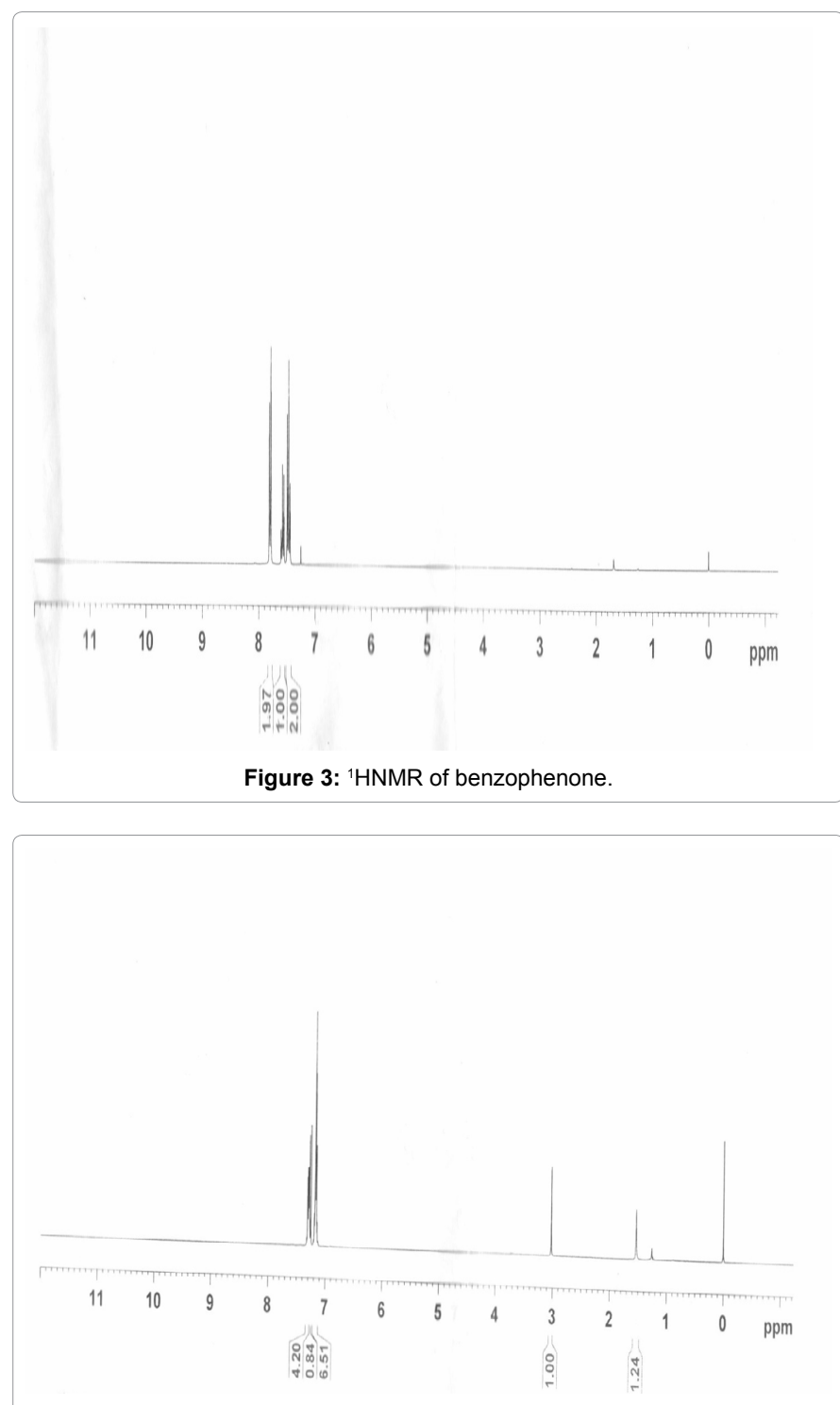

Figure 4: ${ }^{11} \mathrm{HNMR}$ of benzpinacol.

photoreduction of benzophenone catalysed by sunlight using ethyl alcohol as a solvent and reagent. Spectroscopic characterization of compound clearly indicates that benzpinacol was successfully synthesized. In IR spectra after seven days of reaction time carbonyl band at $1720 \mathrm{~cm}^{-1}$ disappeared and new absorption band at 3400-3650 $\mathrm{cm}^{-1}$ for $\mathrm{OH}$ appeared, shows that photoreduction of benzophenone to benzpinacol via sunlight has been completed. ${ }^{1} \mathrm{HNMR}$ spectra for benzpinacol indicates presence of singlet at $\delta 3.0$ for $\mathrm{OH}$ proton Results positively show that solvent ethyl alcohol can be used as an alternative for photoreduction of benzphenone in case of non-availability of isopropyl alcohol.

\section{Key Features of Reaction with Ethanol}

According to news reports issued in March 2017 by Cleveland based industry research firm, The Fredonia Group, says global demand for green solvents derived from natural or renewable resources, will soon reach 2 billion pounds per year. In which ethanol will account for nearly half the growth in green solvents demand through 2020 and thus to remain as world's most prevalent green solvent [11]. 
Citation: Geeta V (2017) Photoreduction of Benzophenone in Green Chemistry Using an Alternate Solvent Ethyl Alcohol. Chem Sci J 8: 165. doi: 10.4172/2150-3494.1000165

- Solar energy is used as a source of catalyzing the reaction.

- Solvent derived from natural source have a minimal impact on the environment.

- Ethanol is cheaper solvent.

\section{Acknowledgements}

The author wishes to thanks Dr. Brijesh Kumar, Head, SAIF, CSIR, Central Drug Research Institute Lucknow, India and their staffs for providing FTIR spectroscopic data. Thanks are also due to College's Principal and Head of the chemistry department for providing me Institutional facilities. Author is especially thankful to her husband Dr. RK Verma, daughter Aditi and son Aditya for their constant support, cooperation, motivation during the research work.

\section{References}

1. Geeta V (2015) Various Areas of Green Chemistry and Safer Environment An Overview. International Journal of Research in Applied Natural and Social Science 3: 87-94.

2. https://books.google.co.in/booksisbn $=1478446498$
3. Prat D, Pardigon O, Flemming HW, Letestu S, Ducandas V, et al. (2013) Sanofi's Solvent Selection Guide: A Step Toward More Sustainable Processes. Org Proc Res Devel 17: 1517-1525.

4. Sherman J, Chin B, Huibers PDT, Garcia-Valls R, Hatton TA (1998) Solvent Replacement for Green Processing. Environ Health Persp 106: 253-271.

5. www.gkpublication.in/IJRR_Vol.4_Issue.5_May2017/IJRR0010.pdf

6. Ashton AQ (2013) Benzene Derivatives - Advances in Research and application 2013 edition, Scholarly Edition, Atlanta, Georgia, USA.

7. James K (1999) Macroscale and Microscale Organic Experiments. 3rd edn. Williamson W, Kenneth L (eds.), J Chem Educ 76: 1492.

8. Preparation of Benzopinacol via Photoreduction of Benzophenone in 2-Propanol (2002) Luzchem Research Inc., Ottawa, Ontario, Canada.

9. Pitts JNJ, Letsinger RL, Taylor RP, Patterson JM, Recktenwald G, et al. (1959) Photochemical Reactions of Benzophenone in Alcohols. J Am Chem Soc 81 : 1068-1077.

10. Agrawal OP (2010) Advanced practical Organic Chemistry. 22nd edn. Goyal Publishing House, Meerut, India.

11. http://www.vsengenharia.com.br/en/blog/ethanol-to-remain-world-s-mostprevalent-green-\%20Solvent 